\title{
Investigación de la comunicación en Argentina
}

\section{Reflexiones sobre la investigación crítica}

\author{
Dra. Paulina Beatriz Emanuelli \\ Profesora de la Escuela de Ciencias de la Información. \\ Universidad Nacional de Córdoba (Argentina)
}

Este trabajo, a modo de pantallazo, propone una travesía por algunas de las problemáticas y orientaciones en las que se ha desarrollado la investigación comunicacional en Argentina. Poniendo especial énfasis en la investigación desde una perspectiva crítica, se la relaciona con el marco contextual en la que se construye. Incursiona en algunos de los desafios y limitaciones a los que esta sometida en el presente y propone algunas reflexiones al respecto.

Se trata, más que de brindar una sistematización, de proporcionar algunos elementos o aportes que ayuden a reflexionar, debatir y aproximarse a objetivos o proyectos que podamos compartir en el campo de la investigación en comunicación.

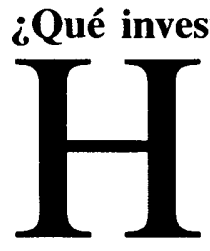

ablar de

ablar de investigación en comunicación implica, en principio, hablar del gastado y complejo tema del objeto de estudio de la comunicación. Sin entrar aquí a discusiones epistemológicas que muestran que los medios masivos de comunicación han constituido $E l o b$ jeto de estudio por excelencia en nuestra disciplina.

Esta centralidad de los medios masivos (fundamentalmente prensa, radio y televisión) en los campos académicos está relacionada con distintos factores.

En principio han sido clave su vertiginoso crecimiento -desde finales de la segunda guerra mundial- y el avance de la tecnología en la última década. La incorporación de los medios a la sociedad y la adopción de nuevas tecnologías han contribuido en la producción de transformaciones socio-culturales, económicas y políticas que los ubican en un lugar de preeminencia en las sociedades contemporáneas.

Para afianzar esta 'centralidad massmediática', también ha contribuido la importancia otorgada a la comunicación por el desarrollismo. Desde 
la década del cincuenta y con mayor énfasis en los sesenta se consideró a la comunicación como generadora de desarrollo en tanto difundiera educación e innovaciones tecnológicas. Esta conceptualización llevó a una propuesta de expansión de los medios masivos ${ }^{1}$ en todo el mundo y especialmente en los países subdesarrollados.

No obstante, la comunicación social y de masas son una realidad integrada por muchos aspectos que se relacionan, involucran y trascienden los medios masivos.

Pensar la comunicación es considerarla como procesos y productos de interacción social en los cuales se inscriben intercambios de sentido que constituyen un entretejido de interacciones ${ }^{2}$.

La comunicación que trasciende las fronteras geográficas, es el espacio donde se diseñan y definen viejas y nuevas relaciones, marcos y reglas para la interacción entre los sujetos, sus identidades y socialización, sus sistemas de normas y valores.

Estas nuevas prácticas construidas en los espacios mediáticos, pero también más allá, reformulan la vida cotidiana, la cultura, la economía y la política.

La complejidad del objeto es una limitación importante ya que no puede ser reducida a un esquema simple sin correr el riesgo de no abarcarlo. De hecho la comunicación puede y debe ser abordada por distintas disciplinas, además debe considerar el contexto donde se produce el proceso comunicacional.

Quede claro entonces que hablar de investigaciones de la comunicación nos remite a un conjunto de prácticas sociales, institucionalizadas o no,

1 Al respecto recordemos los esfuerzos de la UNESCO para lograr la ampliación de redes nacionales de comunicación colectiva. Su motivación era democratizar las comunicaciones pensando que de esta manera se ampliarían las posibilidades de educación (vía alfabetización en masa o educación de minorías poblacionales a bajo costo). De esta manera surge CIESPAL (Centro Internacional de Estudios Superiores de Comunicación para América Latina) con la misión de preparar profesionales para esta gran proliferación de medios especialmente radio y televisión.

2 El discurso es un producto de la interacción social (tanto en lo verbal como en lo extraverbal) entre locutor, auditor y aquello de lo que se habla. La dimensión social del discurso queda clara en Todorov, cuando citando a Bajtin dice: “... La materia lingüística no constituye más que una parte del enunciado; existe una parte no verbal que corresponde al contexto de la enunciación... El contexto extraverbal del enunciado se compone de tres aspectos: 1. El horizonte espacial común a los locutores (compuesto de elementos espacio-temporales, semánticos y evaluativos); 2 . El conocimiento y la comprensión de la situación común a ambos y 3 . La evaluación común de la situación... Cada enunciado cotidiano es como una palabra clave que conocen solamente aquellos que pertenecen al mismo horizonte social..." en TODOROV.: Mikhail Bakhtine, Le Principe Dialogique Ed. Seuil, Paris, 1981. 
que buscan generar un conocimiento sobre o relacionado con la comunicación y que se desarrollan inmersas y condicionadas por distintos factores.

\section{La investigación de la comunicación en Argentina}

La historia de la investigación en comunicación en Argentina, como en todo el mundo ha estado y está influida por las diversas condiciones de producción en las que emerge.

Las transformaciones sociales, culturales y políticas, han definido regulaciones y censuras. Los numerosos quiebres institucionales ${ }^{3}$ marcaron el trabajo intelectual. En algunos casos los investigadores que fueron perseguidos (1976) debieron asilarse en otros países. En otros casos más aberrantes fueron asesinados o desaparecidos y sus libros, al igual que los libros que se consideraban peligrosos, fueron quemados.

La inestabilidad en el plano económico, los sucesivos vaivenes y disminuciones en el poder adquisitivo han incidido también en la producción de investigaciones, generando, cada vez más, un desplazamiento y proliferación de investigadores que se integran a la lógica del mercado.

Los aportes o influencias de la evolución y debate en las ciencias sociales $^{4}$, y su desarrollo en países más avanzados, marcaron el rumbo de numerosos estudios y/o temáticas ${ }^{5}$. Especialmente desde Europa y fundamentalmente Estados Unidos se han sentido influencias marcadas en la evolución de la investigación comunicacional argentina y latinoamericana.

Asimismo, el desarrollo local de los medios de comunicación y la adopción de nuevas tecnologías, delineó tendencias y marcó los tiempos de esta investigación 6 .

3 El orden constitucional fue quebrantado en numerosas oportunidades. La seguidilla de revoluciones se inició en 1930 con el derrocamiento de Hipólito Yrigoyen . Continuó, entre otras, las más significativas: «Revolución Libertadora» en 1955, «Revolución Argentina» en 1966 y «Proceso de Reconstrucción Nacional», la más cruenta de todas en 1976.

4 Fue clave para los 'estudios críticos' el aporte Gramsciano sobre la ampliación del concepto de ideología, la construcción de la hegemonía, el consenso y la conceptualización de clases sociales.

5 Como ejemplo de influencia teórico - metodológica podemos mencionar por un lado la influencia de la sociología empírica norteamericana en los estudios de audiencia o la gran influencia que tuvo en la región el movimiento semiológico (semiótico, en aquel entonces) estructuralista francés de los sesenta e inicios de los setenta en la perspectiva crítica latinoamericana para la búsqueda de ideología en contenidos de los medios.

6 Los estudios sobre televisión por cable o satélite no pudieron desarrollarse antes de 1989, pues fue entonces cuando salió al aire la primera señal lanzada por VCC y se llamó Premier. Recién en la década del noventa la televisión por cable será objeto de numerosos estudios. 


\section{Los comienzos en el marco de Latinoamérica}

En sus comienzos, desde inicios del siglo y hasta los años cuarenta inclusive, el estudio de la comunicación se manifestaba en forma esporádica y ocasional. Era fruto de un esfuerzo e interés personal y no institucional.

En aquel entonces, las grandes disputas de poder estaban localizadas en Europa y los jóvenes países latinoamericanos, algunos con democracias incipientes, cumplían un papel de proveedores de materia prima y se desenvolvían con relativa independencia.

El medio de comunicación predominante era la prensa. En consecuencia el gran énfasis se puso en el estudio del periodismo impreso que fue analizado en sus aspectos históricos, ético- jurídicos, y literarios. De esta forma se realizaron biografías de periodistas eméritos, reconstrucción de perfil e historia de empresas editoras, o se catalogaron periódicos que circulaban en determinada época. A estos estudios de tipo histórico, se agregaron también estudios de crítica literaria y trabajos de interpretación de la legislación que reglamentaba la actuación de la prensa y normaba el comportamiento de los periodistas.

Luego con el impulso y crecimiento de la radio se realizaron algunos estudios de audiencia y propaganda con fines comerciales. Se buscaba la eficacia de la comunicación de manera conductista concibiendo a los individuos como sujetos inactivos fáciles de influir para el consumo.

El panorama comienza a cambiar en la década de los cincuenta y los sesenta con la consolidación de la radio, el cine y una incipiente pero impactante televisión ${ }^{7}$. La prensa creció e incorporó las innovaciones tecnológicas que mejoraron su impresión y calidad del papel. La publicidad se consolidó y diversificó cobrando gran relevancia.

Eran los años de posguerra, Estados Unidos, victorioso, comenzó su proyecto de expansión hacia Latinoamérica. La gran producción de bienes industriales norteamericanos comenzaba a colocarse en los mercados latinoamericanos. Fue clave en esa época la Alianza para el Progreso ${ }^{8}$ que a través de sus propuestas desarrollistas, permitió el ingreso de capitales estadouni-

7 La televisión argentina surge a instancias de una gestión gubernamental y con fuerte contenido político. El entonces presidente Gral. Perón comisionó a dos personas (Yankilevich y Koëble) la tarea de instalar un canal de televisión en Argentina. La primera imagen de LS82 TV Canal 7 fue la captada del acto del 17 de octubre de 1951, realizado en Plaza de Mayo, cuando Eva Perón anunció su renuncia a la vicepresidencia de la nación.

8 Programa aprobado en 1961, en la conferencia de Punta del Este, para el desarrollo económico y social de la América Latina. Impulsado por J. F. Kennedy, se presentó como la posibilidad de cooperación entre EEUU y Latinoamérica, como la posibilidad de disminuir o contener el auge revolucionario de la región. 
denses, a los países de la región. También influyó la supremacía de Estados Unidos en la UNESCO quien presionó por los programas de difusión de tecnologías de la comunicación hacia los países del sur y hasta propusoimpuso líneas de trabajo en comunicación ligadas a los derechos y deberes de los periodistas.

Es así como se inicia un sesgo que aún perdura: «...La investigación sobre comunicación en Latinoamérica ha estado, y todavía lo está , considerablemente dominada por modelos conceptuales foráneos procedentes más que todo de Estados Unidos...» (Merino Utreras: 1985, 30) ${ }^{9}$

De esta actitud expansionista surgen tipos de estudios que tratan de acercar los nuevos productos a la sociedad. Los estudios más significativos de la época fueron los de audiencia y los de opinión pública, los que se sumaron a los anteriormente mencionados.

En este período es importante señalar la acción de $\operatorname{CIESPAL}^{10}$, que tiene gran proyección en todo el continente. Además de entrenar docentes y periodistas, esta institución puso especial énfasis en la investigación. Se podría decir que CIESPAL atraviesa por dos momentos diferenciados. Uno integrado a las teorías existentes (1959 a 1970) y otro de elaboración propia que significó el mayor período de producción original de la región.

En la primera etapa, la perspectiva de abordaje de la comunicación social fue esencialmente la periodística. Coincidiendo con José Marques de Melo y Javier Esteinou Madrid podemos caracterizar la investigación de CIESPAL en esta primera etapa como:

«...dos modelos diseminados por CIESPAL ganan amplitud: los estudios de morfología y contenido de la prensa (metodológicamente orientados por el francés Jacques Kayser) y los estudios sobre el comportamiento del público consumidor de los medios de comunicación (metodológicamente inspirados en las técnicas norteamericanas de lectura y de análisis de audiencia)...» (Marques de Melo: 1985,5)

"...Con apoyo de CIESPAL las teorías organicistas y los métodos cuantitativos con todas sus variantes penetran transparentemente en muchos de los planes de estudio de las escuelas de comunicación. Los esquemas de

9 MERINO UTRERAS, Jorge: «Ciespal en la Investigación» Chasqui № 11, 1985 pag. 30

10 El Centro Internacional de Estudios Superiores de Comunicación para América Latina surge con sede en Quito en el año 1959, por iniciativa de la UNESCO, OEA, la Universidad Central y el gobierno de Ecuador, con el aporte de fundaciones como la Fundación Ford . 
Laswell, Lazarsfeld y Schramm fueron modelos dominantes que durante mas de 10 años se emplearon para comprender la comunicación...»(Esteinou Madrid: 1985,23)

Ya en mitades de la década del sesenta se podían vislumbrar tres grandes líneas de estudios algunos de las cuáles habían empezado a gestarse en épocas pasadas. Los estudios histórico-jurídico (académicos tradicionales), los sondeos de opinión y audiencia (comerciales) y los estudios de contenido (morfológicos).

En Argentina, la investigación seguía siendo escasa, y más bien en ámbitos privados. A nivel público, había una Escuela de Periodismo y Ciencia de la información en La Plata y la producción más importante se concentraba en Buenos Aires donde no había escuelas de comunicación, sino carreras como sociología, filosofía y letras. En ese momento, la investigación se concentraba en el Instituto Di Tella, más exactamente en el Centro de Investigaciones Sociales, donde los estudios dominantes sobre teorías de la comunicación y modelos lingüísticos se enrolaban en corrientes estructurales y semióticas ${ }^{11}$. Mas adelante, comenzaron a crearse numerosas escuelas de Ciencias de la Información y de Periodismo en donde cobraron gran relevancia los modelos teórico metodológicos antes mencionados.

\section{La investigación crítica}

Los años setenta encuentran a la investigación en comunicación atravesada por dos grandes corrientes: por un lado los que aceptan la sociedad como es y que destinan sus trabajos y esfuerzos a sondeos comerciales; dedicándose al perfil de audiencias urbanas, la morfología de los periódicos o a estudios jurídicos e históricos no comprometidos. Eran estudios muy influenciados por la teoría y metodología de la Mass communication research. Por otro lado, comienza a emerger una vanguardia crítica, de inspiración frankfurtiana, que marcará la investigación latinoamericana y argentina.

Sin duda esta vanguardia se encontraba imbuida del espíritu de la época. Recordemos al acontecimiento político más significativo de los aires revolucionarios en Latinoamérica: la revolución cubana de 1959. De allí en más, numerosos movimientos revolucionarios se extendieron en la región.

1 Fundamentalmente se consideran los trabajos de Oscar Massota, Eliseo Verón, y Oscar Steimberg entre otros. 
En la década del sesenta y en medio de un creciente proceso de industrialización, en Argentina las fuerzas populares se vigorizaron y las movilizaciones adquirieron un carácter multitudinario. La rebelión obrero estudiantil de 1969 llamada «Cordobazo» ${ }^{12}$ puso en apuro al régimen militar de J. Carlos Onganía (1966-70) quién debió renunciar. Eran tiempos donde el fortalecimiento del proletariado, los indicios de lucha de clase, acercaban el sueño de la toma del poder por parte del pueblo.

En tanto en el campo de la comunicación, se producen varios acontecimientos importantes. La llegada al poder de la izquierda o nacionalistas en condiciones de legislar o intervenir en los medios masivos hizo necesario estudiar distintos aspectos para poder generar propuestas de intervención. Del mismo modo en el campo teórico, se produjeron transformaciones importantes.

La llegada de Salvador Allende al gobierno de Chile ${ }^{13}$ hizo necesaria una revisión sobre las responsabilidades de los medios de comunicación y la producción de mensajes. En Perú, el gobierno militar de Velazco Alvarado, como parte del Plan Inca ${ }^{14}$ puso en evidencia la relación de poder comunicacional con el poder político y económico.

En Brasil, Paulo Freire ${ }^{15}$ con sus trabajos en educación popular, deja al descubierto junto a la teoría de la dependencia, la dureza del proceso de dominación social: la verticalidad comunicacional y la ausencia de diálogo que lleva a la exclusión de grandes sectores sociales en todo el continente. Una exclusión que está relacionada a la dominación que sufre el pueblo y permite la expansión de los países capitalistas a instancias del subdesarrollo de países más pobres. Es decir, se concluye que el subdesarrollo en la región, no es más que una consecuencia del desarrollo de los países capitalistas, especialmente Estados Unidos.

12 Se llamó 'Cordobazo' porque se produjo en Córdoba, una ciudad metropolitana de la Rep. Argentina, que cuenta con una gran tradición política y cultural. En los años álgidos de represión fue una de las ciudades más apaleadas.

13 La 'Unidad Popular' que ganó las elecciones en 1970, era una coalición política de partidos de izquierda.

14 De corte antiimperialista y antioligárquico, el Plan Inca de 1974, expropia los grandes medios informativos que estaban en manos de la oligarquía y los entrega a las organizaciones sindicales.

15 Pedagogo brasilero, dirigió e inspiró en Brasil un movimiento de alfabetización y posalfabetización de gran alcance, al cual dio fin el golpe militar de 1964. Para Freire la educación es praxis, reflexión y acción del hombre sobre el mundo para transformarlo. Escribió Pedagogía del oprimido y La educación como práctica de libertad. 
El dinamismo político e ideológico imperante en el mundo entero y por ende en América Latina, constituyeron el marco y fermento de una vanguardia intelectual de izquierda. La CIESPAL ${ }^{16}$ misma, realiza una autocrítica sobre su propia evolución y las perspectivas de la investigación en la región produciendo un giro de ciento ochenta grados en sus propuestas. El primer paso fue el reconocimiento de la dependencia teóricometodológica y la necesidad de realizar búsquedas propias en ese sentido.

Argentina no quedó al margen de todo este movimiento «...En aquella época, fines de los sesenta y principios de los setenta, aparece fuertemente el fenómeno de las comunicaciones y sus problemáticas, la necesidad de analizarlas, de investigarlas pero en el marco de un tiempo tramado en lo político ideológico...» (Nicolás Casullo en Mapa Nocturno: 1996, pág. 22).

El rechazo de los legados funcionalistas norteamericanos predominantes llevó a búsquedas que se orientaron en distintos sentidos. Se contextualizó el problema de la comunicación situándolo en las esferas política y económica.

El enfoque crítico de la comunicación se centró en la relación ideología, poder y comunicación. Cambia el concepto de comunicación y se revisa el papel de los medios masivos en la sociedad. Los medios, dicho en palabras de la época, no son sólo transmisores de cultura o información sino 'aparatos ideológicos del estado' ${ }^{17}$ que reproducen la ideología dominante para mantener la dominación y opresión de la clase obrera. En consecuencia medios y procesos de comunicación comenzaron a ser abordados pensando en permitir la participación - inclusión - de los sectores populares mayoritarios.

Esta necesidad de participación se manifestó en varios espacios. Se organizaron distintas agrupaciones profesionales de periodistas y otros tipos de comunicadores y comunicadores sociales. Éstas estaban orientadas a la

16 CIESPAL promovió en Costa Rica 1973, el primer encuentro de investigadores latinoamericanos que se dedicaban a la comunicación. Allí se produjeron dos importantes avances: el reconocimeinto de investigadores que no acordaban con su línea teórica política e inició su propia autocrítica asumiendo los resultados del encuentro. Los resultados del encuentro fueron contundentes: a) reconoció el carácter dependiente de la teoría de la comunicación y de la metodología predominante en la región. B) propuso la búsqueda de alternativas teóricas y metodológicas que puedan ofrecer soluciones a los problemas de la región. C) marca la prioridad de dos aspectos a estudiar: el papel de la comunicación en la educación y en la organización y movilización populares. También realiza una serie de recomendaciones para la investigación coordinada en la región.

Debe aclararse que a raíz de este giro crítico, los recursos económicos vía UNESCO y OEA (dominio de EEUU) fueron recortados drásticamente lo que repercutió en la tarea de CIESPAL.

17 Nótese en la conceptualización utilizada la influencia de Louis Althusser, filósofo marxista que trabaja fuertemente esta idea. 
promoción y defensa de la participación como elemento esencial del derecho a informar y a estar informados. A nivel latinoamericano surgen la Federación Latinoamericana de Periodistas (FELAP), Asociación Internacional de Investigadores en Comunicación (AIERI) y la Federación de Asociaciones de Facultades de Comunicación Social (FELAFACS) entre otras.

Algunos de los estudios más importantes que se realizaron desde esta perspectiva crítica podrían agruparse en las siguientes líneas.

Estudios sobre las formaciones discursivas y los mensajes de la cultura de masas considerando sus estructuras de significación. En Argentina, tuvo una fuerte influencia el estructuralismo francés en la figura del investigador belga Armand Mattelart quien residía en Chile ${ }^{18}$. Sus trabajos de corte denuncista, apuntaban a analizar semiológicamente los rasgos estructurales del discurso de masas (distintos géneros y sus soportes) en su articulación con la ideología dominante. Cabría mencionar la diferencia de encuadre y enfoque metodológico entre la propuesta de análisis de Armand Mattelart y la de Eliseo Verón ${ }^{19}$ (también semiólogo).

Estos estudios permitieron, además del reconocimiento de las huellas del dominador, preparar el campo para la creación de una conciencia crítica en la lectura de los mensajes de la 'cultura de masas'20.

Estudios sobre la estructura de poder -nacional y trasnacional- de los medios de comunicación y las estrategias de dominación instrumentadas por los países centrales (fundamentalmente Estados Unidos) con los países periféricos o semiperiféricos. Este tipo de estudios se referían al flujo comunicacional e informacional y la indagación de las innovaciones tecnológicas relacionadas a la comunicación e información como nuevas formas y sistemas de control sobre las sociedades latinoamericanas.

18 Escribe el libro Como leer al pato Donald donde realizaba una interpretación estructural marxista demostrando la dominación ideológica realizada por los mass media y su vinculación al proyecto imperialista.

19 La discusión giraba básicamente en torno a compromiso político vs. desinterés por la problemática política (política vs lingüística). Al respecto se desató una fuerte polémica que se materializó en el debate entre la revista Comunicación y Cultura que dirigía Héctor Schmucler, quien trabajaba con Mattelart, y la revista Lenguajes de la cuál participaba Eliseo Verón.

20 Son conocidos los trabajos de CENECA sobre la formación de receptores activos que ya en la década del setenta y bajo la dictadura trabajaron con talleres que buscaban elaborar propuestas con los receptores. Pueden citarse entre otros autores a: Valerio Fuenzalida, María Elena Hermosilla, Paula Eduawrds, Gisella Munizaga. 
El tema del Nuevo Orden Mundial de la Información y la Comunicación (NOMIC) fue en su momento un intento internacional democratizador que generó importantes investigaciones. Enmarcado dentro de las peticiones de los Estados de Países No Alineados, en Argel (1973), los problemas del desequilibrio informativo ligado a las desigualdades entre los pueblos fueron cobrando importancia en la UNESCO. En la Conferencia General de la UNESCO de 1976 se constituyó la Comisión Mc. Bride encargada de indagar sobre estos problemas y orientar soluciones. La Comisión concluye su trabajo con el informe Un solo mundo, voces múltiples ${ }^{21}$ en 1980 , en el que confirma el desequilibrio informacional existente entre norte y sur. Propone entonces como solución de estos desequilibrios la transferencia y capacitación tecnológica con bajo costo, a cargo de los países desarrollados y en beneficio de los subdesarrollados. Al iniciar la implementación del 'Programa Internacional de las Comunicaciones' (PIDC) - creado en la Conferencia de Belgrado - ocurre el violento retiro de Estados Unidos y otros países centrales de la UNESCO (1984). Con este acontecimiento, los fondos de la UNESCO se vieron sensiblemente disminuidos. El 'PIDC' no pudo llevarse adelante sin recursos y el tema se fue diluyendo hasta quedar sólo en el lugar del recuerdo. No obstante, los 'estudios transacionales', inspirados en esta temática, fueron la base de la que surgió el Instituto Latinoamericano de Estudios Transacionales (ILET) en 1975 en México. El ILET se dedicaba al estudio de la economía y comunicación y sus trabajos se diseminaron en la región.

Estos estudios aportaron una importante línea de trabajos relacionados con las políticas de comunicación. De esta forma, como reacción y para poner freno a la trasnacionalización, creció la necesidad de formular y evaluar políticas nacionales de comunicación y cultura que promovieran programas de desarrollo acordes con las expectativas de los sectores mayoritarios del pueblo.

Estudios inscriptos en la comunicación popular o alternativa. La comunicación alternativa, muy emparentada con la educación popular (acción, reflexión acción), surge como expresión de un proyecto histórico de cambio y plantea un quiebre con el concepto de comunicación lineal

$21 \mathrm{Al}$ respecto véase MC. BRIDE, Sean y otros Un solo mundo, voces múltiples. Informe de la Comisión Mc. Bride de la UNESCO. Paris, 1980. 
y vertical que se venía manejando desde el funcionalismo. Es la comunicación opuesta, alternativa a los autoritarismos políticos, económicos y culturales propios de la racionalidad del modelo capitalista transnacional. El concepto clave de esta comunicación es que los sujetos se intercomunican. Ya no hay emisor y receptor, sino hay sujetos constituidos históricamente que se relacionan en un intercambio que constituye un proceso dialogal donde ambos interactuan, debaten, se forman en conjunto. Es una comunicación horizontal, democrática no autoritaria.

La comunicación alternativa, en tanto proceso componente de un proyecto histórico de cambio, adquiere un carácter educativo que provee a los sujetos intervinientes de herramientas teóricas y prácticas que apoyan la confrontación que lleva al cambio.

La investigación de esta comunicación, no es ajena a los supuestos y al proyecto que le da sentido. De esta manera surge la investigación acción $^{22}$ (que algunos autores llaman participante ${ }^{23}$ ) como una práctica de indagación de lo real que apunta a la transformación de la sociedad. Es entendida como un proceso de producción de conocimientos que se desarrolla para satisfacer una necesidad surgida de una práctica social; un proceso colectivo de análisis y explicación de lo real, en el cual se entablan unas relaciones horizontales que posibilitan una síntesis entre las experiencias distintas de los sujetos. De esta forma, la investigación - acción unifica los conceptos "conocer» $y$ "hacer», de tal manera que vincula: investigación, planificación, acción y evaluación en un mismo proceso. Ya no se trata de una actividad de indagación ejercida desde 'afuera' del objeto sino ejercida dentro del objeto mismo. En ella, los sujetos intervinientes se convierten en objeto y a su carácter cognoscitivo, propio de la investigación, se suma

22 Thiollent señala como antecedente, además de la educación popular, a un grupo de militantes marxistas que en los sesenta pretendía establecer nuevas formas de comunicación y acción política con los trabajadores a partir de la encuesta realizada por K. Marx. Al respecto se recomienda ver textos de R. PANZIERI y D. LANZARDO, en THIOLLENT, Michel; Crítica Metodológica, Investigación Social y Encuesta Obrera Sao Pablo, Polis, $2^{\mathrm{a}}$ Edición 1981.

23 Al respecto Michel Thiollent hace una diferenciación significativa basándose en que en la Investigación participante los grupos considerados no saben que son investigados y no se movilizan en función de una acción transformadora. En «Investigación - acción» Chasqui n $^{\circ} 10,1984$, Quito, Ecuador. Se pueden consultar sobre el tema del mismo autor «Pesquisa- Açao no campo da comunicaçao socio-politica» en Comunicaçao e Sociedade $N^{\circ} 4$, Sao Pablo, 1980. CONTRERAS BUDGE, E Comunicación Popular Educativa Monografía de CIESPAL, 1984, Quito, Ecuador. 
una dimensión pedagógica donde todos se forman en conjunto teórica y prácticamente. "... el énfasis está por un lado, en la producción y apropiación socializada de conocimientos de una realidad concreta y el otro, en el propio proceso de aprendizaje de los modos de aprenderla.... ${ }^{24}$

Esta investigación ofrece un verdadero desafío para los investigadores ya que debe utilizar métodos y procedimientos que posean rigor científico y a la vez faciliten la participación de sujetos no adiestrados (la comunidad donde se realiza) en esa tarea. Cabe señalar, que el profundo contacto con los grupos implicados en el problema real, marca su limitación: no puede aplicarse a un universo mucho más amplio.

Estos estudios contribuyeron al conocimiento de diversos tipos de innovación y experimentación de nuevas prácticas comunicativas, especialmente con soportes ligeros para los que no es necesaria una gran inversión económica. La investigación - acción se aplicó en el contexto de la comunicación social como forma de captar la información y sus efectos en redes formales que componen determinadas actividades sociales como consumo, trabajo y educación.

En resumen, entre los sesenta y setenta la tríada ideología, poder y comunicación abordados desde una perspectiva semiótica, sociológica pero fundamentalmente política y económica, constituyeron los ámbitos en los que se desarrolló la investigación crítica de la comunicación en Argentina.

Estos estudios quedarían postergados o serían continuados en otros países a causa del golpe de estado conocido como «Proceso de Reconstrucción Nacional».

Como consecuencia de la devastación producida por el golpe militar de $1976^{25}$, la investigación crítica en Argentina sufre un deterioro significativo. En la década del sesenta, el imperio de las ideas modernas pudo enfrentar la dictaduras militares de Juan Carlos Onganía (1966/70), Roberto Levinstong (1970/71) y Alejandro Lanusse (1971/1973) y hasta enriquecer al peronismo de 1973 .

24 CONTRERAS BUGDE, E; Comunicación Popular Educativa Monografía de CIESPAL, 1984, Quito, Ecuador. pag 185.

25 Se creó una junta militar constituida por representantes de las tres fuerzas armadas: J. Videla, E. Massera y O. Agosti. El 30 de marzo el Grl. Videla fue elegido presidente y el Congreso, los partidos políticos y las organizaciones sindicales fueron declarados fuera de la ley e incautados sus bienes. 
Pero aquella euforia general provocada por la movilización de los sectores obreros, sindicales y estudiantiles fue rápidamente aniquilada con la represión más dura ${ }^{26}$.

El terror gobernó sobre las instituciones, las personas, las ideas y los sueños. El campo intelectual fue especialmente acosado.

El grueso de intelectuales críticos se exilió en otros países y los que se quedaron se diseminaron lejos de las grandes urbes. Muchos fueron a México, otros países de América Latina, y a Europa principalmente a España.

En los países latinoamericanos ya había antecedentes de exilios, un gran número de chilenos luego del golpe militar de Augusto Pinochet en 1973, habían iniciado la dolorosa senda.

En los primeros años (1976 - 1980) la supervivencia en el país fue espantosa.

En un ocultamiento total, se vivían las persecuciones y los secuestros. Pero no se hablaba de ellos. Las políticas institucionales (cualquiera de ellas) se orientaban en primera instancia a la 'limpieza ideológica' y desde luego no había segunda instancia ninguna. Todo era sospechoso. La persecución y la sospecha se instalaron como herramientas de control coercitivo. Millares de desaparecidos, desolación ...

Libros quemados, bibliotecas desvastadas, se pretendió un imposible: borrar a Karl Marx y su pensamiento de la historia. Aunque ni siquiera fuera su pensamiento, bastaba con que sonara sospechoso. Heriberto Muraro cuenta que:

«...El ejercito quemó la edición completa del primero de mis libros ${ }^{27}$ pero tuvo la gentileza de no quemar a su autor. Alguna vez vi, en una foto publicada por una revista de la Editorial Atlántida, para mi deleite, que en el museo de la subversión de Campo de Mayo se exhibía un fascículo mío sobre los efectos de la comunicación de masas, que había escrito para Centro Editor. En realidad era un refrito de escritos norteamericanos que hablaba de los líderes afectivos y de los líderes instrumentales. Estaba dentro de la más estricta ortodoxia de la communication research, si se quiere...» (Heriberto Muraro, en Mapa Nocturno: 1996, pág. 81).

26 El sindicato de Luz y Fuerza fue uno de los primeros en intentar una huelga contra el golpe militar. Integrantes de la conducción gremial (Oscar Smith, entre ellos) fueron secuestrados y desaparecidos.

27 Se refiere a Neocapitalismo y Comunicación de masa, Ed. Universitaria de Buenos Aires, Bs. As. 1974. 
Las Universidades fueron intervenidas, las ciencias sociales y la filosofía fueron especialmente acorraladas. Sus planes de estudios y contenidos fueron manoseados y bastardeados.

El resultado de toda esta represión social, la prohibición de reunirse y tratar determinados temas provocó un debilitamiento del tejido social, un condicionamiento y control de la interacción social que llevó a un encapsulamiento, repliegue en lo personal, de los individuos. La gente no se reunía, apenas se saludaba y a veces ni siquiera eso.

¿Cómo trabajar o pensar en ese contexto?

Los primeros años de la dictadura fueron para la investigación de total inmovilidad. Se produjo un distanciamiento de la temática, un repliegue en lo personal y familiar. Se buscó generar un espacio que permitiera reconstruir los esquemas de pensamiento y comprensión pues eran éstos a los que apuntaban destruir los métodos represivos.

Hacia el final de la dictadura militar ${ }^{28}$, desde algunos organismos privados comienzan a reorganizarse espacios de discusión sobre la temática. En Buenos Aires instituciones como CLASCO, dirigida en ese momento por Francisco Delich, o CEDES, dirigida por Oscar Landi, constituyeron espacios de encuentro para varios investigadores del área que estaban en el país.

Con la vuelta a la democracia, y poco a poco, los investigadores que estaban en el exterior comenzaron a volver. Los que estaban en el interior se acercaron a las grandes ciudades.

El encuentro fue muy duro. Se habían vivido experiencias absolutamente distintas. Los que venían de afuera, si bien habían sufrido el desarraigo del exilio y el choque de la adecuación a culturas diferentes, habían seguido con sus trabajos, reflexiones y estudios. No transitaron encarcelamiento, ni persecución, ni siquiera el encapsulamiento o el terror. Los que se habían quedado, querían salir de su ostracismo pero no era fácil.

Fantasmas que se reencontraban más allá del dolor. Mundos distintos que comenzaban a consolarse, escucharse, comprenderse...Con evoluciones intelectuales diferentes pero con ganas de volver y seguir creciendo.

La vuelta a la democracia, con la recuperación de la libertad y de las instituciones constitucionales, fue terreno propicio que permitió la reconstruc-

28 En 1981 asume R. Viola y en 1982 F. Galtieri quien ordenó la ocupación de las Islas Malvinas. Como deterioro de la imagen militar por la derrota de Malvinas y la crisis económica que comenzaba a vislumbrarse asume el Grl. R. Bignone. Es durante su gobierno que se llama a elecciones para retornar a la democracia. 
ción y arranque en el campo intelectual. En 1985 se abrió la carrera de comunicación en la Universidad de Buenos Aires. Nuevos ímpetus y aires renovados comenzaron a soplar en el campo. Los equipos de investigación empezaron a constituirse y a funcionar. Viejos temas postergados ocuparon la centralidad: comunicación educativa ${ }^{29}$ y popular, trasnacionalización, y políticas culturales comenzaron a recobrar su auge.

A mediados de los ochenta con la apertura democrática, la investigación crítica argentina iniciaba su participación en los debates y trabajos con el resto de los países latinoamericanos gracias a los esfuerzos personales de los investigadores y algunas instituciones privadas que los apoyaban.

Sin embargo nada fue igual que antes. El mundo intelectual argentino había cambiado. Argentina y el mundo se estaban transformando, porque fundamentalmente las ideas estaban cambiando.

El neoliberalismo con fuertes bases neoconservadoras empezaba a instalarse.

El modelo económico que cobraba fuerzas proponía un estado reducido, que con el pretexto de disminuir el déficit fiscal, dejaba el camino de las comunicaciones libre a las empresas multinacionales. De esta manera perdieron sentido las discusiones sobre políticas comunicativas y planificación de la comunicación estatal pues los medios no pertenecerían más al estado. Se había derrumbado la idea de un Estado protector de los intereses públicos por no decir algo que ya sonaba obsoleto: 'los intereses de las mayorías desposeídas'. La transnacionalización pasa a ser vista como un estadio anterior pues comienza a concretarse el proceso de globalización.

Al mismo tiempo se produjo un gran avance de las nuevas tecnologías, que curiosamente están en poder de estas mismas empresas, y que afectó directamente a los capitales nacionales.

En el campo de la televisión argentina es donde puede apreciarse con más claridad estas consideraciones.

En 1989 se inició la privatización de las posesiones del estado en medios de comunicación entre las que se encontraban dos canales de televisión que fueron adjudicados a empresas periodísticas nacionales. ${ }^{30}$

29 Como ejemplo vale decir que el Primer Congreso de Comunicación Educativa tuvo lugar en 1985, cuando en otros países hacia años que se estaba trabajando e intercambiando en la temática.

30 La ley que impedía el acceso de la prensa nacional a los medios audiovisuales fue modificada por la Ley 22285 art. 65 . 
Las pequeñas o medianas empresas de televisión por cable, frente a los altos costos de reconversión tecnológica y la difícil competencia con los grandes grupos de Buenos Aires, encuentran más rentable la venta de sus compañías a seguir trabajando en el mercado. De esta manera se siguen consolidando los grupos como MultiCanal, Clarín, VCC, Cablevisión y Telefé y detrás de éstos las empresas telefónicas y los capitales extranjeros.

Poco a poco los capitales nacionales comienzan a perder terreno frente a los extranjeros. Dados la alta rentabilidad de las empresas telefónicas y su capacidad para afrontar la reconversión tecnológica (el 50\% de la red telefónica está digitalizada) pueden competir sin problemas con los grupos multimedia o unirse a ellos ${ }^{31}$.

Políticamente, en la década de los ochenta es cuando comienza el principio del fin de la utopía marxista. La desintegración de la Unión de Repúblicas Socialistas Soviéticas (URSS) y la creación de la Comunidad de Estados Independientes ${ }^{32}$ marca el cierre de un el ciclo en la historia humana. Esta crisis del marxismo en general, tuvo en Latinoamérica y en Cuba en especial gran repercusión. Los movimientos de izquierdas, sensiblemente debilitados, se replegaron dejando el terreno libre o con poca resistencia a la política neoliberal (a veces camuflada) que comenzaba a consolidarse.

Esta transformación del marxismo y la consecuente revisión de algunas de sus bases, se siente también en el mundo de las ideas. Algunas de sus categorías de análisis consideradas insuficientes a la luz de experiencias concretas, son examinadas. Se adoptan los conceptos de ideología y hegemonía planteado por Antonio Gramsci acercando la dimensión cultural al campo de la comunicación.

De esta forma se comienza a pensar la compleja trama de factores que intervienen en la construcción del consenso especialmente en el campo cultural en donde la comunicación tiene un papel central. En este terreno es donde se construye el consenso en una constante negociación e intercambio de producciones simbólicas.

31 Esto se hizo más notorio en la década del noventa cuando por necesidades de reconversiones tecnológicas los capitales norteamericanos ingresaron sin dicultad «... En abril de 1994, VCC establece un acuerdo de aporte tecnológico y financiero con la empresa norteamericana Continental Cablevisión por 150 millones de dólares, convenio que representa el $50 \%$ de la empresa; MultiCanal, también en 1994, se asocia al grupo Citicorp Equity Investiments, vendiendo el $30 \%$ de sus acciones por 150 millones de dólares; y así mismo Cablevisión, en diciembre de 1994, vende el $51 \%$ de sus acciones a TCI (Tele- Communications Inc.) por 300.000 millones de dólares...» (SCHUMCLER y TERRERO: 1996, 76).

32 Luego de un largo proceso conmarchas y contramarchas, se firma la constitución de la Comunidad de Estados Independientes en diciembre de 1991 en Minsk. 
Es importante señalar aquí la gran influencia de los estudios culturales, que básicamente a finales de los ochenta pero fuertemente en la década del noventa marca los estudios de la región.

Uno de los conceptos claves de esta corriente ha sido el de «cultura» desarrollado por Raymond Williams (1977) como un «sistema total de vida» que se constituye a través de «prácticas» o «actividades significativas». La construcción de un orden social o macro se construye en las prácticas y relaciones microsociales, es decir en la vida cotidiana a través de las actividades e interacción de la vida diaria de los agentes sociales. Se incorpora entonces una concepción materialista de la cultura, que influida por la categoría de «hegemonía» gramsciana ${ }^{33}$, se visualiza como el resultado de un conjunto de prácticas y relaciones determinadas por las condiciones materiales de existencia de los agentes sociales. Esta construcción del orden social dominante incluye resistencia y luchas tanto como la subordinación de alternativas. Se determina en función de los distintos modos de distribución social y la hegemonía otorga interconexión a prácticas, valores y sentidos en tanto resoluciones concretas de realidades económicas específicas.

Estamos hablando de un concepto de hegemonía, no como superestructura, sino un proceso dinámico que tiene límites y presiones específicas cambiantes y que se materializa en la misma vida cotidiana.

Volviendo al concepto de «práctica» y «cultura», se puede decir entonces que en las prácticas de significación culturales la comunicación se plantea como «negociación» en una interacción entre el receptor y los productos culturales propuestos. En esa interacción, el receptor acepta, rechaza o transforma los significados disponibles y cobran especial importancia las mediaciones en un sistema social que se materializa en la vida cotidiana.

De este modo, los procesos de comunicación no constituyen un producto para y a partir de los medios masivos sino el conjunto de intercambio e interacción que producen una «cultura viva». Los procesos de comunicación se conciben como una articulación de prácticas de significación en un campo de fuerzas sociales.

33 Antonio Gramsci (1891-1937) fue director de la revista L'Ordine Nuovo y uno de los fundadores del partido comunista italiano. En 1926, siendo diputado, fue detenido y condenado por un tribunal a 20 años de prisión, donde definitivamente murió. Su producción de mayor contribución al marxismo quedó plasmada en los famosos «Cuadernos de la cárcel» que fueron publicados en 1947. Su trabajo se basó en un rechazo al determinismo economicista en el análisis de la relación entre base y superestructura. Uno de los conceptos más importantes planteados por Gramsci fue la categoría de «hegemonía» que se entiende como la capacidad de un sector o grupo de sectores aliados, de generar consenso favorable para sus intereses y hacerlos equivaler como generales. 
La producción cultural de los medios industriales de comunicación se encuentra con un público que también es sujeto productor de cultura en tanto es agente activo en la vida social y en sus condiciones históricas. Para comprender el funcionamiento de los medios de comunicación tiene importancia esencial estudiar las estructuras de la sociedad y la situación histórica concreta. Variando las condiciones históricas de existencia de las fuerzas sociales varían las «negociaciones» en la interacción.

De esta forma se establece la importancia de la vida cotidiana en la construcción de ideología y consenso y se define un rol activo del receptor en el sostenimiento y construcción de la hegemonía.

Otro desplazamiento importante se produce en el campo del estructuralismo. Se pone en tela de juicio el carácter inmanentista de los análisis y en consecuencia conceptos con que se venían manejando los análisis del mensaje y se plantea la necesidad de unir mensaje a contexto. De esta forma las investigaciones se orientan a la búsqueda de aspectos extra e intertextuales de los procesos de significación que acercan el estudio del discurso al contexto y su historia.

Queda claro entonces que desde una perspectiva u otra se establece un renovado interés por la relación de la comunicación y la cultura en la que se produce.

En centralidad cultural se materializa en diversos estudios:

Estudios sobre los procesos de constitución identitaria de los sujetos de sectores populares. Se estudian el papel de la comunicación y la cultura en la construcción de identidades colectivas como modelos reproductores de lo transnacional ${ }^{34}$. Se buscan las diferencias entre lo nacional y lo regional por oposición a lo foráneo, en ese momento transnacional, luego sería el modelo emergente de la globalización.

Estudios sobre nuevas tecnologías. Los estudios sobre nuevas tecnologías no son nuevos, por el contrario. Lo que varía es la modalidad de enfocarlos. Al comienzo se abordaron desde una perspectiva de detectar las relaciones internacionales de dependencia. Se estudiaban entonces, para detectar su función en la transnacionalización de la cultura.

34 Se entiende por proceso de trasnacionalización, ya no la imposición de un modelo económico sino la internalización de un modelo político con el que el capitalismo hace frente a su crisis a finales de los setenta y comienzos de los ochenta. 
Poco a poco las perspectivas cambian y comienzan a indagarse en su espesor cultural. Se estudia el consumo, la adopción, impacto y naturalización en distintos ámbitos (públicos y privados), de las tecnologías nuevas del campo de la comunicación, información y entretenimiento. Se busca indagar sobre la transformaciones que producen en la vida cotidiana $y$ en el trabajo de la gente.

Otra perspectiva absolutamente distinta, relaciona la aparición de las tecnologías con un momento histórico de la humanidad, un nicho cultural, que hace posible su existencia. Se produce un desplazamiento de la idea de tecnología como innovación, al de efecto de transformaciones o necesidades socio-culturales pretéritas que le dan cabida..

También desde esta perspectiva histórico filosófica, se propone indagar las transformaciones culturales que han producido las tecnologías no sólo en el consumo, sino en los campos de circulación como el desempeño laboral, los oficios creados a partir de ellas.

Estudios sobre culturas populares. En 1982, Jesús Martín Barbero en su trabajo «Cultura Popular y Comunicación de Masas» presentado al Primer Foro Internacional sobre Comunicación y Poder en Lima, propuso tres líneas de trabajo al respecto:

- De lo popular a lo masivo. Se refiere a cómo se constituye históricamente lo masivo como el desarrollo de ciertas virtualidades presentes en la cultura del S. XIX. Esta perspectiva histórica está presente en la mayoría de los estudios actuales, aunque no conserve las mismas características.

- De lo masivo a lo popular. Se refiere a estudiar la cultura de masa en cuanto negación de los conflictos a través de los cuales las clases populares construyen su identidad. Se trata, en primer lugar, de indagar sobre los dispositivos de masificación: de despolitización, control y de desmovilización. En segundo lugar, la mediación, esto es las operaciones mediante las cuales lo masivo recupera y se apoya sobre lo popular. Se trata entonces de investigar la presencia en la cultura masiva de códigos populares de percepción y reconocimiento, de elementos de su memoria narrativa e iconográfica.

- Los usos populares de lo masivo. Esta línea de indagación se refiere a qué hacen las clases populares con lo que ven, con lo que leen, cuales son 
gramáticas de recepción, de decodificación. Se trata de descubrir los procedimientos en los que se encarna otra lógica de la acción: la de la resistencia y la réplica a la dominación.

Esto significa ubicar el problema a otro nivel, ya no él de los medios, sino el de las mediaciones y los modelos culturales.

Estudios de recepción y consumo mediático de los sectores populares. De la última línea planteada por Martín Barbero se desprenden estos estudios nutridos de varios aportes teóricos. A estos conceptos vertidos por Martín Barbero se suman los de «prácticas culturales significantes» y otros emanados de los estudios culturales británicos, además de los aportes semiológicos de intertextualidad, y aportes de otros autores latinoamericanos como los de Néstor García Canclini. Esta es en principio la base sobre la que en distintos sentidos evolucionaron los estudios de recepción latinoamericanos y argentinos.

De esta forma, la investigación crítica pasó de una etapa denuncista e ideologista con una marcada concepción instrumental de los medios masivos, a una etapa de estudio centrada en el campo cultural y las mediaciones intervinientes en la comunicación.

Ya no sólo se habla de medios de comunicación como reproductores de ideología dominante sino también de un espacio de negociación en el campo cultural, donde la hegemonía se construye por el consenso y en una permanente interacción entre la clase fundamental y las clases subalternas y/ o auxiliares. En esta negociación en el campo cultural, los receptores de las clases subalternas y/o auxiliares aceptan, resisten o rechazan es decir 'negocian' los contenidos hegemónicos que les proponen los medios.

Si bien estos aportes fueron de suma importancia en el campo, presentan algunas limitaciones que deberán ser superadas:

El excesivo énfasis en la autonomía de la audiencia. Ha habido una tendencia a plantear la actividad de la audiencia como una forma de resistencia total a los mensajes mediáticos. Hay autores que tienden a plantear la actividad del receptor como omnipotente. Debe quedar claro que la audiencia es activa, pero no por eso poderosa.

La excesiva tendencia a homogeneizar impropiamente los textos y las audiencias sin respetar fronteras culturales ni políticas sin poner esas prácticas en su propio contexto. La adopción de ciertos lineamientos teó- 
rico metodológicos de los estudios culturales sin considerar la realidad argentina y latinoamericana.

La confianza en las «cualidades polisémicas de los textos». De repente el receptor es tan activo que los mensajes cobran cualquier sentido y hasta sus mecanismos significativos de «cierre» se disuelven en la actividad del receptor

Pero la limitación más fuerte es el excesivo énfasis en la fragmentación de los microprocesos dejando de lado las macroestructuras. Hay una reducción a lo sicológico y antropológico, a las prácticas cotidianas que deja de lado las prácticas culturales articuladas como relaciones de poder que constituyen la perspectiva de comprensión macro social.

\section{El estudio de la comunicación hoy}

Sobre la perspectiva de abordaje de la investigación de la comunicación cada vez hay mas acuerdo en que dada la complejidad de los procesos comunicacionales, es esencial considerar el marco donde se produce esa comunicación.

Considerar este contexto implica indagar aspectos vinculados con tecnologías y medios sus relaciones económicas, políticas, culturales y sociales.

A modo de esquema, he aquí las cuestiones que deben considerarse:

La evolución y estado actual de los medios masivos a nivel tecnológico. El desarrollo mediático a nivel empresarial y su implicancia económica. Las transformaciones sociales, culturales y políticas que marcan el desarrollo massmediático.

Procesos y modelos de comunicación, sus modos de abordaje en directa relación con la evolución y desarrollo de las ciencias sociales.

El marco civilizatorio, socio-cultural, político y económico que constituye la matriz del espacio cultural donde se produce el fenómeno comunicacional objeto de estudio.

Este último punto quizás es clave para encontrar una visión totalizadora o global en los que se inscriben los procesos comunicacionales. Hay que pensar que lo comunicacional, así como la cultura toda, se delimita en lógicas más amplias, civilizatorias, de concepción de vida, de mentalidad de época. 


\section{Al decir de Calabrese:}

«... Toda la cultura de una época se expresa, en mayor o menor cantidad y de un modo más o menos profundo, en la obra de cualquiera. Precisamente evitando jerarquías y marginaciones entre textos es posible descubrir el retorno periódico de algunos rasgos que distinguen nuestra mentalidad de la de otros períodos..." 35

Esto no significa generar en una actitud escéptica o conformista respecto a la irreversiblilidad de la lógica civilizatoria, sino más bien reconocer la génesis donde se produce la comunicación para poder describir y comprenderla.

Otra cuestión importante es reconocer que la dimensión compleja de la comunicación trasciende un único ámbito disciplinar y debe ser ubicada en el ámbito de las ciencias sociales como área del conocimiento más allá de las disputas de legitimación entre una u otra disciplina académica.

Del mismo modo que otras disciplinas en las ciencias sociales, la comunicación acuñó su intento de legitimarse como ciencia constituyendo su cuerpo teórico. Esta tendencia a buscar la autonomización de la 'Ciencia de la Información' sobre la base de la 'Teoría de la Información' que se consolidó entre fines de los sesenta y setenta en Argentina y en América Latina, marcó una limitación teórica que dejó de lado muchos de los aspectos contextuales imprescindibles para la comprensión del fenómeno comunicacional. Ya no puede pensarse la comunicación sin aportes de la historia, política, antropología, semiología, economía, sociología, psicología, y fundamentalmente la filosofía como necesarios e imprescindibles para comprender la comunicación.

Lo cierto es que por un factor $u$ otro, la investigación en comunicación ha producido una serie de estudios en general descontextualizados y fragmentados.

El problema no es la fragmentación, tal vez deberíamos reconocer con Martín Barbero (1987) que «...los tiempos no están para síntesis...» . Sino más bien que estamos en un período de ebullición donde debe sostenerse un amplio trazo de libertad para posibilitar la generación de conocimientos y teorías. Son tiempos en los que es prioritario pensar, discutir, compartir, crecer y producir.

35 CALABRESE OMAR, La era neobarroca, Ed. Cátedra, 1989, Madrid. Pág. 12. 


\section{Desafíos en la investigación crítica}

Los noventa con el pleno auge y expansión de la lógica del mercado, son terreno fértil en una sociedad en donde los valores de la modernidad están en jaque.

Estados nacionales reducidos cuya única responsabilidad es la de disminuir el gasto público. Gremios y sindicatos desarticulados e inmovilizados, desocupación en franco crecimiento, naciones debilitadas económica y culturalmente son sólo algunas de las características del mundo actual.

Vivimos en una sociedad que en poco tiempo ha sufrido profundas transformaciones. La ausencia de trascendencia, consecuencia de la falta de ideales y la desacralización de la modernidad establecen su dominio en estos tiempos.

Éste es el contexto que enmarca la investigación crítica actual.

En los sesenta y setenta los espacios de producción crítica se ubicaban fuera de las instituciones públicas. Actualmente con la desocupación y las carencias económicas, los intelectuales se debaten entre el mercado, la crítica y la subsistencia. Las instituciones privadas regidas fundamentalmente por la lógica mercantil, no son el campo propicio para la investigación crítica.

El proyecto neoliberal imperante condiciona también la ideología académica institucional y el mercado laboral profesional. Se está imponiendo una forma de trabajo. Una lógica de funcionamiento que más allá de la moda, se caracteriza por la lucha del mantenimiento de la posición personal en el mercado intelectual.

El compromiso que otrora fuera ideológico político, de transformación social, es hoy de posicionamiento individual en el campo laboral.

Estamos en un estado de emergencia y supervivencia donde lo superficial, la estética ,el simulacro, la imagen, el hedonismo y la falta de futuro son lo imperante.

La propia universidad argentina, en plena transformación y adecuación a esta lógica mercantil refuerza e impulsa el modelo de producción y reproducción numérica en contraposición de la calidad de lo producido.

Esto se hace más visible en el Programa de Incentivos ${ }^{36}$ donde no se paga por pensar, sino por investigar y publicar. De esta manera se crea un

36 El Programa de Incentivos surge en 1994, desde el Ministerio de Educación de la Nación con el objetivo de incentivar la carrera académica y la investigación en las Universidades Nacionales. Luego de categorizar a los docentes como investigadores se paga un sueldo cuatrimestral extra (dependiendo de la categoría y dedicación del docente) por realizar investigaciones en el campo académico donde se desempeña. 
aparente crecimiento explosivo de la investigación. Ahora bien, este programa en muchos casos ha sido promotor de investigaciones y grupos de investigación, pero en otros ha generado como respuesta de supervivencia en el sistema, estrategias que se materializan en una tendencia al simulacro y la apariencia en lugar de realizar investigaciones reales.

Aún así con todo lo que ello implica, hoy más que nunca, la universidad pública debe preservarse como espacio para el libre pensamiento y la generación de conocimientos. Los esfuerzos deben orientarse a la permanencia y avance de las temáticas críticas en detrimento de una rutina mercantil académica.

Por eso, en esta realidad académica institucional de las universidades públicas es imprescindible pensar el lugar de la investigación de la comunicación crítica y los rumbos que debe seguir.

En principio la posibilidad de intervención de los setenta con el acceso al poder de gobiernos democráticos populares marcó una urgencia para la intervención que en la actualidad se ve como lejana. Existe la idea de que uno puede tomarse un tiempo para pensar la comunicación pues no hay urgencias en la planificación de políticas de intervención social.

Este es el primer punto que se debe reconsiderar. Que las condiciones no estén dadas, no significa perder la claridad de para qué se investiga. Conocer para transformar. 'Pensar la comunicación' es imprescindible pero también lo es, generar propuestas de acción.

La falta de urgencia de intervención puede llevar a la ilusión de que se tiene todo el tiempo por delante. Grave error, porque los esfuerzos de intervención deben darse en instancias micro o macro de acuerdo a las posibilidades que surjan.

En este 'pensar la comunicación' se han profundizando líneas de trabajo en el campo cultural, desde una perspectiva histórica, antropológica y política y se ha dejado de lado la cuestión económica. Pareciera que en la cultura se han disuelto los conflictos político económicos.

Claramente se vislumbra un desplazamiento clave en los últimos diez años. La economía que en los setenta fue determinante, en los ochenta pasó a ser irrelevante frente al increíble desarrollo de los trabajos en el campo cultural. Es importante entonces, recuperar la relación entre economía y política, pero sin dejar de lado las otras miradas. Pareciera que estamos sujetos a modas que inagotablemente expiran cuando un investigador u otro recu- 
pera tal o cual autor. Falta reflexión, conocimiento y seguimiento sobre nuestra propia historia.

Justamente sobre esto es fundamental crear espacios de discusión y autorreflexión colectiva mas allá de los prejuicios teórico metodológicos y de la luchas mezquinas de posicionamiento individual con sus mutuas y correspondientes descalificaciones. Hace falta una madura discusión con el tema pero también con el modo de conocer la comunicación armonizados en un 'para qué investigar' que permita el avance de la investigación crítica argentina. 


\section{Bibliografía:}

- BELLO, GILBERTO y otros: «Concepciones de la comunicación y crisis teórica en América Latina» Revista Dialogos n 26, México, 1993.

- CASULLO, Nicolás: Mapa Nocturno «Diálogo con los investigadores argentinos de la comunicación/cultura/medios» 1996, Buenos Aires. Pag. 22.

- CONTRERAS BUDGE, E: Comunicación Popular Educativa Monografía de CIESPA, 1984, Quito, Ecuador.

- ESTEINOU MADRID, JAVIER: «CIESPAL y la ciencia de la comunicación» Revista Chasqui n ${ }^{\circ}$ 11, Quito, 1985.

- FUENTES NAVARRO, Raúl: «El estudio de la comunicación desde una perspectiva sociocultural en América Latina», Revista Dialogos nº 36, 1992.

- MARTÍN BARBERO, JESÚS: «La comunicación desde la cultura: Crisis de lo nacional y emergencia de lo popular» Revista Alternativa Latinoamericana, junio, 1985.

- Idem, De los medios a las mediaciones Ed. Gustavo Gilli, 1987

- MARQUES DE MELO, José: «La investigación latinoamericana en comunicación» Revista Chasqui $\mathrm{n}^{\circ}$ 11, Quito, 1985.

- RIVERA, Jorge: La investigación en comunicación social en Argentina Ed. Punto Sur. Buenos Aires, Argentina, 1987.

- SCHMUCLER, Héctor y TERRERO, Patricia: «Innovaciones tecnológicas y transformación de la televisión en Argentina» en Voces y Culturas $n^{\circ} 9,1^{\circ}$ semestre, Barcelona, 1996, España.

- WILLIAMS, Raymond: Cultura, Sociología de la comunicación y el arte, Paidós, Barcelona, 1981. 